\title{
Teaching across Cultures: Student-Led Modules in a Human Rights Course
}

Becca McBride

ABSTRACT Human rights, ethnic conflict, democratization, colonialism, and developmentmany upper-level political science courses contain content that is understood differently across cultural contexts. Equipping students to appreciate diverse perspectives on these issues is a challenge that requires creative pedagogical strategies, regardless of whether all students come from the same region of the United States or the class has more than half international students. Professors in both environments have the complex task of guiding students to navigate disparate viewpoints. This article demonstrates the pedagogical potential of an integrated approach to student-led class modules based on a two-semester experiment using a Global Politics of Human Rights course at a small liberal arts college with a large population of international students. One section of the same course was taught in each semester with identical course material but with two different sets of student participants. After situating the challenges and the strategy within the growing literature on active learning, the article provides basic details of the pedagogical approach and three examples of the modules. It concludes with methods for assessing the effectiveness of student-led class modules.

\section{PEDAGOGICAL CONTEXT: CHALLENGES AND THE STRATEGY}

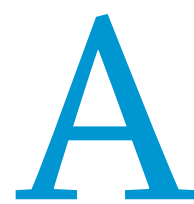
ctive-learning strategies are pedagogical tools that include small-group discussion, case-study exploration, simulations, role playing, and debates that require students to actively engage with course materials. Numerous studies show that active-learning strategies help students to navigate disparate perspectives in several ways. First, they immerse students in real-life situations and help them to evaluate complex concepts and to think strategically (Bromley 2013; Glasgow 2015; Omelicheva and Avdeyeva 2008; Switky 2014; Trueb 2013). This immersive experience encourages students to explore diverse perspectives (Nance, Suder, and Hall 2016; Switky 2014) while also helping them to identify their own assumptions (Blackstone and Oldmixon 2016; Bromley 2013, 820; Switky 2014). Second, active-learning strategies enable students to use their diverse lived experiences to inform one another's understanding of course material (Asal 2005; King and Sen 2013; Macauley 2016), which can be difficult to facilitate in traditional lectures. This increases student responsibility for their own learning and their peers' learning (Asal 2005;

Becca McBride is a learning specialist who most recently served as assistant professor of political science at Calvin College in Grand Rapids, Michigan. She can be reached at becanya@hotmail.com.
Frombgen et al. 2013), especially when a more collaborative approach allows groups of students to "interpret, question, challenge, or even critically 'break down' larger frameworks of understanding" (Centellas and Love 2012, 507). Third, active-learning strategies incorporate students with diverse learning styles (Bromley 2013; Hunzeker and Harkness 2014), which often are culturally informed through primary- and secondary-education experiences.

Most active-learning literature describes discrete assignments with high levels of instructor control in four design components: educational objectives, design parameters, guidelines for action while in exercise, and assessment (Kille 2002, 272). My method departs from this approach. First, instead of an assignment, I present a strategy for integrating student-led class modules into course design. This approach can be applied to any course in which the content is differently understood across cultures. Second, I demonstrate how active-learning strategies can increase students' ability to incorporate diverse perspectives when instructors strategically surrender control of the exercises to them. In my approach, instructors control the educational objectives and assessment of the exercise throughout the semester, but students control the design parameters and guidelines for action within each iteration of the exercise. This approach frees students to frame course material in terms of their own lived experience 
and diverse perspectives, allows them to actively facilitate deliberation among their peers, and reverses the role of professor and student such that students become joint producers of course material rather than merely classroom consumers.

\section{CLASS CONCEPTS}

The Global Politics of Human Rights course is divided into three units with an individually submitted two-page paper and a student-led module as the capstone experience of each unit. The course is designed to move thematically from broadly theoretical to case specific, and the goal is to equip students for understanding individual-, state-, and system-level causes of human rights challenges as well as solutions in each level. Each unit has a guiding question to prompt individual student responses and community debate at the end of the unit. Throughout the semester, displaced people (Sriram, Martin-Ortega, and Herman 2010). This final unit builds on previous units by exploring why the international human rights regime sometimes can fail to protect the most vulnerable in the international system, especially in light of political disagreement and limited resources. Student papers and the class module must answer the following question: "Who are the most vulnerable in the international system and how can they be protected?"

\section{CLASS-MODULE COMPONENT}

In the first week of each class, I divided the 30 students into three class-module groups that were diverse in terms of cultural identity and gender. Studies show that intentionally constructing diverse groups increases student learning (Moore 2014) and I had the additional goal of encouraging cross-cultural collaboration.

\section{In my approach, instructors control the educational objectives and assessment of the exercise throughout the semester, but students control the design parameters and guidelines for action within each iteration of the exercise.}

students also individually write two policy-oriented papers on a human rights challenge of their choice. The problem-analysis paper identifies the individual-, state-, and system-level causes of a human rights challenge and uses a case to illustrate those causes. The policy-recommendation paper investigates solutions to the same problem on each of the three levels.

The first unit focuses on theoretical foundations as students explore diverse perspectives on the foundation for human rights. For example, we use scholars including Donnelly (2013) to explore societal consensus as a foundation for human rights; Wolterstorff (2013) to explore Christian theology as a foundation for human rights; and Sachedina (2009) to explore Islamic theology, tradition, and law as a foundation for human rights. This unit equips students to understand contestation over foundations for human rights as a basis for subsequent discussions about variation in human rights protections across national contexts. Student papers and the class module must answer the following question: "What is the 'best' foundation for human rights? Why?"

The second unit focuses on procedural and legal aspects, and students investigate the norms, treaties, and institutions of the global human rights regime. For example, we examine treaties designed to protect vulnerable groups, prevent discrimination, and constrain state behavior during war. We also investigate how regime type and domestic legal systems shape variation in states' commitment to and compliance with human rights treaties. This unit builds on the previous unit by examining how the international community has moved beyond disagreements over human rights foundations and has used treaties to institutionalize human rights norms. It also prepares students to examine cases of vulnerability that the international human rights regime seeks to address. Student papers and the class module must answer the following question: "How do domestic politics impact human rights protections?"

The third unit focuses on case studies as students explore patterns of human rights violations and responses to them around three uniquely vulnerable groups in the international system: women (Hudson et al. 2012), children (Smolin 2006), and internally
Groups were assigned one of the three class-module periods and tasked with structuring their ideal class around answering the question of the day. In line with giving up control of the design parameters and guidelines for engagement within each module, I provided students with only the three parameters for the module: it must be interactive and inclusive, it must be planned collaboratively, and it must creatively address the question of the day. One week before the class module, the students submitted class readings and a class plan, which gave me the opportunity to screen the module for problematic content. I defined the objective of the assignment as helping students gain a deeper understanding of the unit material through creative engagement.

The modules are designed to help students engage with course material in three ways. First, students individually answer the question of the day in the preparatory phase. Second, the students planning the module collaborate to frame the material from their unique perspectives and experiences, and this process of becoming peer instructors helps to better "teach the teachers" (King and Sen 2013, 622). Third, the students participating in the module explore diverse perspectives on the unit material within the module. At the end of each module, I processed the experience with the whole class, focusing on lessons learned from this iteration that could improve future modules. I also provided student planners with feedback on what was most effective about the module and what could have increased its effectiveness.

Although this pedagogical tool is easily applicable across contexts, several conditions increase its effectiveness. First, as a collaborative assignment, the group must be collectively assessed, which encourages students to share the responsibility for the assignment instead of competing with one another (Bain 2004, 35; Centellas and Love 2012, 507). In my courses, each member of the group receives the same grade regardless of how well individual students participate. In only one of the six iterations did a student engage in significant free-riding activity; I addressed the behavior with that student. Second, it is important to choose a first group that sets the bar high for all class modules, which admittedly is easier when professors are already familiar with some 
of the students. Third, this exercise is most effective when the subject matter under consideration is contested and complex.

The following sections describe three iterations of the class modules to illustrate how students collaboratively engaged with diverse perspectives on the course material.

\section{ITERATION 1: THE "BEST" FOUNDATION FOR HUMAN RIGHTS?}

The day of the first module, the class began with one leader reading a decree that "in an effort to create a more-inclusive environment for all, from this moment all religiously specific clothing (and absorb the costs of commitment by paying money) or not commit (and lose a set number of reputation points). Committed states rolled dice: an even number meant they lived up to their treaty obligations and received reputation points; an odd number indicated they committed some act that violated their obligations and they paid for it in reputation points. The reputation costs for violating treaty obligations were higher for democracies than for dictatorships. Each country first had to decide whether to commit to the treaty, based on the risk that a future regime might violate it. When there was a violation, the violating state would have to defend its behavior in a press conference. At the end of each iteration,

\section{The day of the first module, the class began with one leader reading a decree that "in an effort to create a more-inclusive environment for all, from this moment all religiously specific clothing and supplies will be forbidden and confiscated."}

and supplies will be forbidden and confiscated." The other nine student leaders entered the room, dressed identically in dark clothing, and proceeded to confiscate any items that violated the decree, including clothing, jewelry, notebooks, textbooks, and electronics (e.g., iPhones with a Bible app). Student leaders then divided the class into three groups: a "secular" group, a "Muslim" group, and a "Christian" group. Each group had 15 minutes to discuss privately-from the perspective of their assumed identity-which of these three groups was most likely to adopt such a policy. After this period of internal debate, each group presented its position with no comment from the other groups. Student leaders then facilitated a larger debate in which the students were allowed to advocate for their group in light of the other groups' presentations. Finally, students were allowed to assume their own identity and engage in the same debate.

There were three interesting outcomes of this iteration. First, the exercise heightened students' ability to identify with diverse perspectives. Because I teach at a private, religiously affiliated college, most students are more familiar with a Christian or secular perspective than a Muslim perspective. Yet, when assigned that identity, students in the Muslim group were adamant in their defense of their assigned perspective. In fact, when they were allowed to assume their own identity, many remained firm in defending the Muslim perspective-despite their lack of personal lived experience with it. Second, several international students were able to frame their arguments in terms of their lived experience in other countries, which had not emerged previously in lecture or discussion sections on the same course material. Third, the act of participation in a student-led module built trust in the classroom and set an expectation of collaboration that carried throughout the other iterations.

\section{ITERATION 2: THE IMPACT OF DOMESTIC POLITICS?}

In the second module, student leaders divided the class into four groups: two dictatorships and two democracies. Each table had a student-leader acting as a United Nations representative. Each country began with $\$ 100$ and reputation points (i.e., 50 for dictatorships, 100 for democracies). One leader presented five decades of human rights treaties throughout the class period. For each treaty, each government had to decide to commit to the treaty the student leader took the class through the global landscape of commitment to and compliance with that treaty.

This exercise was instructive in two ways. First, students were engaged and excited as they learned about unit themes through participation in the game. The exercise was rooted in an important paradox of commitment and compliance-dictatorships rarely lost because they faced fewer costs for both commitment and a lack of compliance. I conveyed this paradox during lectures; however, when they experienced it firsthand, the lesson was more impactful. Second, students again were required to "put on" an identity that was foreign-especially those who had to defend their actions as dictatorships. This exercise helped students experientially understand the cost-benefit calculation influencing state commitment to and compliance with human rights treaties.

\section{ITERATION 3: THE MOST VULNERABLE?}

In the final module, student leaders assigned each participant an identity as either a vulnerable person (i.e., woman, child, or internally displaced person) or as an advocate. Student leaders were either facilitators or government officials. The game had three rounds, each beginning with the setup of a situation such as a natural disaster or a civil war. Student leaders explained that government officials would vote to protect one category of vulnerable people at the end of each round. The task was to advocate for a particular group so they would be protected in that round. Complicating the game were various restrictions and instructions written on cards, known only to the person holding them. For example, none of the children could speak directly to government officials-they had to find an advocate who would speak for them. Despite the fact that children were vulnerable in every situation, it was difficult for them to advocate for themselves; someone had to do it for them. Moreover, results of the first round (i.e., natural disaster) had implications for other rounds. When government officials decided to protect women after the first round, several of the children-according to instructions on the card-became child soldiers. Because the second situation was civil war, the game could unfold in an unpredictable and complex manner, without knowing how individuals would act in their role.

Student leaders later communicated to me that they had no idea if the game would work. Much depended on whether their 
peers would participate with enthusiasm. However, this module, more than any other, effectively demonstrated the course concepts. When students were forced to assume the role of a vulnerable person-with all of the inherent limitations-they could better understand the complications in protecting that for different types of regimes"; students were graded based on their ability to synthesize information from the semester. Many used specific examples from the student-led modules in their answers, demonstrating that the modules helped them to better understand course content. Third, course-evaluation feedback

\section{In the final module, student leaders assigned each participant an identity as either a vulnerable person (i.e., woman, child, or internally displaced person) or as an advocate. Student leaders were either facilitators or government officials.}

category. This brief exercise allowed students to live the experience of a vulnerable person (admittedly, in a stylized manner) and to connect experientially with the complications of providing for their protection.

\section{CONCLUSION: ASSESSMENT AND CHALLENGES}

Although all six iterations across the two semesters were of high quality and effective, these three examples were the modules that most strongly impacted student learning. Even variation in module quality did not undermine their effectiveness in deepening student engagement with the material and increasing their appreciation for diverse viewpoints. In fact, the variation in quality became an important teaching tool during the processing period at the end of each module. As the instructor, I could highlight how missteps-such as unclear instructions, too much dead space between segments of the exercise, and not thinking carefully about incorporating non-native English-speaking students-could be improved in future iterations to increase all student learning. The processing periods modeled for students how risk embedded in early iterations could be instructive for future groups as they sought to innovate the assignment. Carefully managed group feedback also helped students to build trust with one another, working together as a class to enhance everyone's learning.

I used three formal assessment tools to evaluate the strategy's value as part of the course: informal peer feedback and debriefing, student performance on the final exam, and student feedback in course evaluations. First, in post-exercise processing, students were most complimentary of the role-playing aspects of the modules, which helped them to appreciate diverse perspectives. Students also verbalized how the student-led framing of situational contexts brought to life important historical information. This confirmed research showing that students perform better in groups when they think of the group as tackling a real-life problem instead of merely fulfilling a course requirement (Bain 2004, 128; Centellas and Love 2012; Switky 2014). Students also overwhelmingly credited the effectiveness of the modules to the fact that their peers led the exercise. In the first two groups, students said knowing that "their turn was coming" made them participate in ways that helped the presenters succeed. In the third group, participants essentially viewed themselves as "returning the favor" for those times when the members of that group had participated in previous modules.

Second, student performance on the final exam provided further evidence of the effectiveness of this approach. The open-book exam asked open-ended questions including "Explain how commitment and compliance (to international law) works differently further demonstrated this strategy's impact on student learning. When asked to identify which course components advanced their learning, at least two thirds credited the student-led modules, giving specific examples of how they increased their understanding of course material.

This integrated strategy for deepening students' understanding of disparate perspectives on contested material helped them achieve course goals, made them more engaged with course material, helped them retain course information, and made them more likely to collaborate across diverse perspectives. Whereas it certainly is an effective strategy to guide students through instructor-led simulations with proven success every semester, the strategy of giving control of specific aspects of active-learning exercises to students can increase their creativity and collaboration while also using diversity in their perspectives and experience as a teaching tool. This pedagogical tool is simple and easy to implement, and it works across various types of courses and student compositions. In fact, the collaboration required for the assignment to be successful increases the possibility that more diverse voices-in terms of ability, background, identity, and interests-are incorporated into the classroom.

\section{ACKNOWLEDGMENT}

I especially thank Sung Hun Choi, Laju Eresanara, and Shiki Hino for their work as research assistants on this project; and Brooke Ackerly and Melissa Snarr, whose use of class modules in my own graduate seminar was the foundation for my development of the pedagogical approach for teaching human rights to undergraduates in diverse environments described in this article.

\section{REFERENCES}

Asal, Victor. 2005. "Playing Games with International Relations." International Studies Perspectives 6 (3): 359-73

Bain, Kenneth. 2004. What the Best College Teachers Do. Cambridge, MA: Harvard University Press.

Blackstone, Bethany, and Elizabeth Oldmixon. 2016. "Assessing the Effect of Breakout Sessions on Student Success and Satisfaction." PS: Political Science \& Politics 49 (1): 117-21.

Bromley, Pam. 2013. "Active Learning Strategies for Diverse Learning Styles: Simulations Are Only One Method.” PS: Political Science \& Politics 46 (4): 818-22.

Centellas, Miguel, and Gregory J. Love. 2012. "We're Off to Replace the Wizard: Lessons from a Collaborative Group Project Assignment." PS: Political Science \& Politics 45 (3): 506-12.

Donnelly, Jack. 2013. International Human Rights. Boulder, CO: Westview Press.

Frombgen, Elizabeth, David Babalola, Aaron Beye, Stacey Boyce, Toby Flint, Lucia Mancini, and Katie Van Eaton. 2013. "Giving up Control in the Classroom: Having Students Create and Carry out Simulations in IR Courses.” PS: Political Science \& Politics 46 (2): 395-9. 
Glasgow, Derek. 2015. "Political Theory Simulations in the Classroom: Simulating John Locke's Second Treatise of Government." PS: Political Science \& Politics 48 (2): $368-72$.

Hudson, Valerie M., Bonnie Ballif-Spanvill, Mary Caprioli, and Chad F. Emmett. 2012. Sex and World Peace. New York: Columbia University Press.

Hunzeker, Michael A., and Kristen A. Harkness. 2014. "The Strategy Project: Teaching Strategic Thinking through Crisis Simulation.” PS: Political Science $\mathcal{E}$ Politics 47 (2): 513-17.

Kille, Kent. 2002. "Simulating the Creation of a New International Human Rights Treaty: Active Learning in the International Studies Classroom.” International Studies Perspectives 3 (2): 271-90.

King, Gary, and Maya Sen. 2013. "How Social Science Research Can Improve Teaching." PS: Political Science \& Politics 46 (3): 621-9.

Macaulay, Fiona. 2016. "Heart, Head, and Hands: Intercultural, Experiential, and Applied Gender Learning in a Peace Studies Department." PS: Political Science \& Politics 49 (3): 566-70.

Moore, Ryan T. 2014. "Overcoming Barriers to Heterogeneous-Group Learning in the Political Science Classroom." PS: Political Science \& Politics 48 (1): 149-56.
Nance, Mark T., Gabriele Suder, and Abigail Hall. 2016. "Negotiating the Transatlantic Relationship: An International, Interdisciplinary Simulation of a Real-World Negotiation." PS: Political Science \& Politics 49 (2): 333-8.

Omelicheva, Mariya Y., and Olga Avdeyeva. 2008. "Teaching with Lecture or Debate? Testing the Effectiveness of Traditional versus Active Learning Methods of Instruction." PS: Political Science \& Politics 41 (3): 603-07.

Sachedina, Abdulaziz Abdulhussein. 2009. Islam and the Challenge of Human Rights. Oxford: Oxford University Press.

Smolin, David. 2006. "Overcoming Religious Objections to the Convention on the Rights of the Child." Emory Law Review 20: 81-110.

Sriram, Chandra Lekha, Olga Martin-Ortega, and Johanna Herman. 2010. War, Conflict and Human Rights: Theory and Practice. London: Routledge.

Switky, Bob. 2014. "Simulating a Foreign-Policy Dilemma: Considering US Humanitarian Intervention." PS: Political Science \& Politics 47 (3): 682-6.

Trueb, Bettina. 2013. "Teaching Students to Write for Real Life: Policy Paper Writing in the Classroom." PS: Political Science \& Politics 46 (1): 137-41.

Wolterstorff, Nicholas. 2013. Journey toward Justice: Personal Encounters in the Global South. Grand Rapids, MI: Baker Academic. 